\title{
Contradiction and Double Binds in COVID-19 Face Covering Recommendations
}

\author{
R. Tyler Spradley, Ph.D. ${ }^{1^{*}}$, Elizabeth L. Spradley, Ph.D. ${ }^{1}$ \\ ${ }^{1}$ Stephen F. Austin State University.
}

\begin{abstract}
The global coronavirus pandemic incited swift public health recommendations and education in the United States and throughout the world to reduce the spread of the virus. In the U.S., the White House Coronavirus Task Force, the "Slow the Spread" campaign in 15 and 30-day increments, the Centers for Disease Control and Prevention (CDC), and other public health organizations and representatives weighed in on the role of face coverings to counter COVID-19 threats to public health. Face coverings became a contested public health recommendation. This article rhetorically analyzes contradiction in COVID-19 face covering recommendations and the ensuant double-binds. Analysis of press conferences, national public health websites, and the "Slow the Spread" campaign reveals contradictions in individual risk-averse public health recommendations, specifically face coverings. Contradictions were categorized into: uncover-cover, risky-risk averse, voluntary-recommended-required, and politically right-left. Implications of contradictory messages create double binds for the public seeking to adhere to public health recommendations for personal and public safety. Double binding public

health messages undermine public health goals because double binds often result in maladaptive, inappropriate responses. Conclusions assert that to be a responsible citizen of personal and public health in a viral pandemic is a contested and contradictory accomplishment.
\end{abstract} *Correspondence to Author: R. Tyler Spradley Ph.D.

Stephen F. Austin State University. How to cite this article:

R. Tyler Spradley, Elizabeth L. Spradley. Contradiction and Double Binds in COVID-19 Face Covering Recommendations. International Research Journal of Health Education, 2020; 3:13.

Keywords: COVID-19; Contradiction; Double Binds

\section{eScîPub}

eSciPub LLC, Houston, TX USA.

Website: https://escipub.com/ 


\section{Introduction}

Quite a bit of scholarly attention has been allocated to the study of communication of health messages and how audiences perceive them. From meta-studies examining gain and lossframe messages ${ }^{[1]}$ to the use of guilt to change attitudes and intentions, ${ }^{[2]}$ persuading people to cease risky health behaviors or adopt new health behaviors is challenging for those in public health, medicine, and the social sciences engaged in this work. What about when health messages are contradictory?

Conceptualized as no win situations, double binds provide allusive or false choices ${ }^{[3]}$ that often stem from contradictory messages. Because the choices presented are less than ideal, contradictory, or penalizing, choice is like smoke and mirrors. You can see it, but you cannot grasp it. You can imagine it, but you cannot find its substance. Rhetorical scholars have long been interested in the communicative construction of double binds. For example, feminist rhetoricians have examined double binds on female politicians, ${ }^{[4,5]}$ female athletes, ${ }^{[6]}$ and female professionals. ${ }^{[7]}$

This study extends such interest to messages aimed at educating the public about health, specifically messages about face coverings during the early COVID-19 pandemic outbreak in the U.S. Both the CDC and World Health Organization did not recommend face coverings for the general public early on in the COVID-19 outbreak, but each of those influential organizations changed their face covering tune and were both widely criticized in the media ${ }^{[8]}$ about their original positions. Citing reasons related to shortages and asymptomatic spread data to name a few, each of those organizations respectively rebooted their face covering messaging and began disseminating face covering health campaign messages. Of interest to scholars is how the face covering recommendations changed and in what ways did contradictions emerge that created double binds for the public participating in risk reduction.

\section{Objective}

The purpose of this rhetorical study is to explore the face covering recommendations to slow the spread of COVID-19 and the double binds in the health education messaging that ensued from contradictory messaging.

\section{Methodology}

For this study, we employed rhetorical analysis to face covering messages by the U.S. White House Coronavirus Task Force, the "Slow the Spread" campaign in $15^{[9]}$ and 30-day ${ }^{[10]}$ increments, the CDC, and other public health officials in the U.S. in March through June of 2020. Rhetorical analysis is commonly used in the analysis of health messages, and we adopted a critical approach to attend to contradictions in face covering recommendations. This is consistent with scholars like Mocarski and Bissel ${ }^{[11]}$ that use a critical rhetorical approach to tease out contradiction between health promotion and entertainment. To accomplish this, we viewed live and recorded press conferences and reviewed print and electronic material through the CDC and White House's websites keeping a log of contradictions in face covering recommendations for the general public. As needed, we also viewed appearances of the U.S. Surgeon General or other public figures on broadcast news outlets or available through YouTube. Our findings in the subsequent section identify four types of face covering contradictions: 1) uncover-cover, 2) risky-risk averse, 3) voluntary-recommended-required, and 4) politically left-right.

\section{Findings}

Face coverings can be categorized differently, but the most general classification that differentiates face coverings as medical or non-medical cloth, and while face covering type has been intermingled in the contradictory messages, most often the contradiction of face coverings have been associated with: 1) uncover-cover to prevent viral spread and contraction of COVID-19, 2) the social construction of risky-risk averse attributions with face covering behaviors by public health figures and organizations, 3) whether or not the face covering recommendation is framed as voluntary-recommended-required, and 4) the politicization of face coverings as a left-right affiliation. The following section takes each of 
these contractions one-by-one to unpack how public health messages constituted each contradiction.

\section{Uncover-Cover}

The initial stance of the Whitehouse Coronavirus Task Force and CDC was that the general public did not need to use face coverings unless they were symptomatic. The bulk of press briefings held in March 2020 by the task force focused on personal protective equipment, ventilators, hospital capacity, modeling, testing, contact tracing, social distancing, and sheltering-in-place, but the focus was not on the use of face coverings to reduce COVID-19 risk. Even as late as April 2, 2020 President Trump [12] opened the task force briefing urging the public to do the following: "Maintaining social distance, practicing vigorous hygiene, and staying at home are your most effective ways to win the war and to escape danger." The following day on April 3, 2020, the CDC reversed the face mask recommendations to include the public using cloth coverings. ${ }^{[13]}$ This first contradiction simply notes the variance in recommendations initially to uncover the face to eventually cover the face, but the second contradiction delves into the attributions of uncovering-covering as related to health risk.

\section{Risky-Risk Averse}

When providing a justification for not wearing a mask, public health officials and organizations cited a false sense of protection. In other words, face covering may be risky for members of the public whom do not exhibit symptoms of COVID19. On March 31, 2020 the Surgeon General Dr. Jerome Adams appeared on the television show Fox and Friends ${ }^{[14]}$ telling the public that masks protect sick people from infecting others, but that masks did not protect people from touching their faces with the virus. He went on to say that masks may cause lax on social distancing and may cause consumers to purchase personal protective gear in shortage for medical practitioners. His advice was directly referencing both CDC and World Health Organization (WHO) guidelines and justifications, but his advice struck a different tune when the CDC changed face covering recommendations.
One day later on the American Broadcasting Company's morning news show, Good Morning America, ${ }^{[15]}$ the Surgeon General hinted at face covering changes ahead. He began by repeating the original recommendations backed by the $\mathrm{CDC}, \mathrm{WHO}$, and his office based on the lack of scientific evidence that masks prevented the wearer from contracting the virus. The Surgeon General went on to say that new data regarding asymptomatic spread suggests that there is public benefit from mask wearing. He stated that he had asked the CDC to revisit the face covering recommendations with a caveat that the public continue social distancing and not purchase masks intended for medical use.

In less than four days, face coverings went from a risky health behavior to a risk averse behavior. On April 3, 2020 the CDC ${ }^{[16]}$ released a video of the Surgeon General demonstrating how to make a cloth face covering at home with items like a scarf, bandana, or t-shirt. While questioned during subsequent press conferences about the shift in recommendations based on risk, the health educational materials including video and print issued by the CDC and Surgeon General demonstrating cloth face covering use did not address reasons for the change. The face covering messages, instead, focused on self-efficacy by demonstrating how to make and use cloth masks at home so that the public felt capable of risk averse face covering practices. While self-efficacy is a recommended practice in behavior change messaging (see work on Social Cognitive Theory, ${ }^{[17,18]}$ Health Belief Model, [19] and the Extended Parallel Process Mode ${ }^{[20]}$ to name a few), these messages failed to address the contradiction posed by the change in face covering riskiness.

\section{Voluntary-Recommended-Required}

Third, face covering mandates have varied from organization to organization, municipality to municipality, and state to state in the U.S. sometimes dependent upon the ability of people to social distance and the degree to which the locale is "open" for business. Because of these variations, face coverings have been voluntary, recommended, and required, which sends mixed 
messages regarding risk reduction behaviors. To illustrate, in our local municipality and state, face coverings were voluntary May through June, but as our place of employment re-opened, face coverings were required, which creates a discrepancy between behaviors at the grocery store and work. Such discrepancies amongst masking mandates and the public's choice to wear masks fed into the fourth and find contradiction that we noted in face covering rhetoric left or liberal versus right or conservative.

\section{Politically Left-Right}

The fourth contradiction politicized face covering behaviors by affiliating them with either the liberal, left, Democratic party or with the conservative, right, Republican party in the U.S. Politicization of non-medical cloth face coverings is evident in the leader of the White House Coronavirus Task Force briefings, Republican President Donald J. Trump. When announcing the shift in face covering recommendations on April 3, 2020, President Trump [21] responded to reporters questioning him about his own masking behaviors. "I don't think l'm going to be doing it," stated the president and went on to give a brief explanation as why including health and presidential duties, and based on news reporting from that day, rapid COVID-19 testing is being conducted for people interacting with president. This admission by the president and images from a visit to an Arizona's Honeywell factory with the president unmasked, ${ }^{[22]}$ generated a deluge of speculation that President Trump, as the Republican party leader, was speaking for all conservatives and functioning as an unmasked example. Further fueling the politicization of mask wearing, images and reports of the June 20, 2020 Trump Rally in Tulsa, Oklahoma revealed the president speaking in front a crowd of masked and unmasked attendees. [23]

With attention mounting around the politicization of mask behavior, other public figures began to directly address it. The North Dakota Governor Doug Burgum ${ }^{[24]}$ held a press conference on May 22, 2020 stating, "If we could just skip this thing that other parts of the nation are going through where they are creating a divide either it is ideological or political or something around mask or no mask." He went on to call for empathy and explain that, "If someone is wearing a mask, they are not doing it to represent what political party they are in or what candidates they support. They may be doing it because they have a five-year-old child who is going through cancer treatments." This study will not rehash all of the reporting on the politicization of masking, but it is important to note, that behavioral modeling of political figures and heightened news coverage of mask politicization only added to the murkiness of face covering health messages that plagued the U.S. from March through June of 2020.

\section{Discussion}

Despite contradictions, early indicators from rapid response surveys published in the CDC's Morbidity and Mortality Weekly Report ${ }^{[25]}$ specified that face covering recommendations were adopted at a greater rate between April and May with a prevalence increase from $61.9 \%$ to $76.4 \%$ when leaving their home. While the survey sampling used quota and statistical weighting to better represent the U.S. population, data is not necessarily helpful in understanding how things like political affiliation or a contradictory face covering messages impacted behavioral practices. Nor does such survey data help understand how local face covering recommendations and policies that vary in term of voluntary, recommended, or required impact behavioral practice. Given the relationship of contradiction to double binds, the implications of double binds in COVID-19 face covering messaging remain concerning.

As public health campaigns and messaging aim to reduce health risks, increase healthy behavior choices, and change health outcomes, double binds threaten public health campaign goals. Wood and Conrad ${ }^{[26]}$ point out that double binds vary in the degree to which they are binding and result in three types of inappropriate maladaptive responses 1) acceptance, 2) counter-disqualification (incongruent response), and 3) withdrawal. At the juncture in which contradiction arose, it seems prudent for the task force and 
CDC in the U.S. to have acknowledged the contradictions, provided explanations for the contradictions, and reinforced positive masking outcomes for individual risk reduction and public safety. Additionally, the face covering messages from the Surgeon General and CDC demonstrating homemade cloth face coverings and how to properly wear face coverings were issued after three of the four contradictions were noted. With temporally-bound message contradictions, later messaging should be contextualized for the public to believe and adopt new masking messages.

\section{Conclusions}

In closing, for those in public health education, there are many lessons to be learned from the U.S. response to face covering messages. Generally speaking, health messages aimed to educate the public and prevent them from exposure to health risks are more effective at encouraging preventative behaviors when they are clear, framed as gain messages, and prompt self-efficacy. ${ }^{27]}$ Contradictory messages likely have an adverse effect on clarity, gain frames, and selfefficacy, especially when considering the double binds that the public experience with contradiction. Despite ongoing public health recommendations and policies regarding face coverings, early COVID-19 messaging may function to undermine clearer, less contradictory messages issued later. Additional research is needed to investigate the effect of contradictions on attitudes and behavioral intent, but this study sheds light on the way's health messaging generate double binds.

\section{Acknowledgement}

The authors would like to thank the Academy of Communication in Healthcare 2020 Virtual Research Forum attendees for their feedback on this study.

\section{References}

[1] Gallagher, K. M., \& Updegraff, J. A. (2012). Health message framing effects on attitudes, intentions, and behavior: A meta-analytic review. Annals of Behavioral Medicine, 43, 101-116. doi:10.1007/s12160-011-9308-7

[2] Xu, Z. \& Guo, H. (2018). A Meta-Analysis of the Effectiveness of Guilt on Health-Related Attitudes and Intentions, Health Communication, 33
(5), 519-525, DOI: 10.1080/10410236.2017.127 8633

[3] Bateson, G., Jackson, D. D., Haley, J., \& Weakland, J. (1956). Toward a theory of schizophrenia. Behavioral science, 1(4), 251-264.

[4] Mandell, H. (2015). Political wives, scandal, and the double bind: Press construction of Silda Spitzer and Jenny Sanford through a gendered lens. Women's Studies in Communication, 38, 57-77. DOI: 10.1080/07491409.2014.995327.

[5] Sheeler, K. H., \& Anderson, K. V. (2013). Woman president: Confronting postfeminist political culture. College Station: Texas A\&M University Press.

[6] Crosby, E.D. (2016). Chased by the double bind: Intersectionality and the disciplining of Lolo Jones. Women's Studies in Communication, 39(2), 228-248. DOI: 10.1080/07491409.2016.1 172388.

[7] Wood, J. T., \& Conrad, C. (1983). Paradox in the experiences of professional women. Western Journal of Speech Communication, 47, 305-322.

[8] Why one expert says healthy people should wear DIY face masks. (2020 March 30). Washington Post, retrieved from https://www.washingtonpost.com/video/national/health-science/whyone-expert-says-healthy-people-should-weardiy-face-masks/2020/03/30/c238a368-b2fa481a-8f0c-dea376ab994d_video.html.

[9] The White House. (2020 March 16). 15 days to slow the spread. Retrieved from https://www.whitehouse.gov/articles/15-daysslow-spread/

[10] The White House. (2020 April). 30 days to slow the spread. Retrieved from https://www.whitehouse.gov/wp-content/uploads/2020/03/03.16.20_coronavirus-guidance_8.5x11_315PM.pdf

[11] Mocarski, R. \& Bissell, K. (2016). Edutainment's impact on health promotion: Viewing the Biggest Loser through the social cognitive theory. Health Promotion Practice, 17(1), 107-115. DOI: 10.1177/1524839915613026.

[12] Remarks by President Trump, Vice President Pence, and members of the Coronavirus Task Force in press briefing. (2020 April 2). Retrieved from https://www.whitehouse.gov/briefingsstatements/remarks-president-trump-vice-president-pence-members-coronavirus-task-forcepress-briefing-17/

[13] Liptak, K. (2020 April 3). Trump announces new face mask recommendations after heated internal debate. CNN. Retrieved from https://www.cnn.com/2020/04/03/politics/trumpwhite-house-face-masks/index.html. 
[14] U.S. Surgeon General explains why CDC recommends public does not wear masks [video file]. (2020 March 31). Retrieved from https://video.foxnews.com/v/6145988945001\#s $\mathrm{p}=$ show-clips.

[15] ABC News Good Morning America. (2020 April 1). U.S. Surgeon General details spread of coronavirus and debate over masks [Video]. YouTube.

https://www.youtube.com/watch?v=VDue2PIm$\mathrm{kIQ}$

[16] Centers for Disease Control and Prevention. (2020 April 3). How to make your own face covering [Video]. YouTube.

https://www.youtube.com/watch?v=tPx1yqvJgf4

[17] Bandura, A. (1991). Social Cognitive Theory of Self-regulation. Organizational Behavior and Human Decision Processes, 50, 248-287. www.uky.edu/ eushe2/BanduraPubs/Bandura1991OBHDP.pdf

[18] Bandura, A. (1998). Health promotion from the perspective of social cognitive theory. Psychology and health, 13(4), 623-649.

[19] Rosentock, I.M, Strecher, V.J., \& Becker, M.H. (1988). Social Learning Theory and the Health Belief Model. Health Education Quarterly, 15(2), 175-183.

[20] Witte, K. (1994). Fear control and danger control: A test of the extended parallel process model (EPPM). Communications Monographs, 61(2), 113-134.

[21] Liptak, K. (2020 Arpil 3). Trump announces new face mask recommendations after heated internal debate. CNN. Retrieved from https://www.cnn.com/2020/04/03/politics/trumpwhite-house-face-masks/index.html.

[22] The White House. (2020 May 6). President Trump visits Honeywell [Video]. YouTube. https://www.youtube.com/watch?v=k5a99$\mathrm{pFmQI}$

[23] NBC News. (2020 June 20). Trump holds rally in Tulsa, Oklahoma [Video]. YouTube.

https://www.youtube.com/watch?v=THmEyiBhb RM

[24] National Governors Association. (2020 May 26). ND Gov. Doug Burgum - May 2020 masks [Video]. YouTube.

https://www.youtube.com/watch?v=VAiHcSpOEYo

[25] Fisher, K.A., Barile, J.P., Guirin, R., Esshert, K.L.V., Jeffers, A., Tian, L.H., Garcia-Williams, A., Gurbaxani, B., Thompson, W., \& Prue, C.E. (2020 July 14). Factors associated with cloth face covering use among adults during the COVID-19 pandemic - United States, April and
May 2020. Morbidity and Mortality Weekly Report, 69. Retrieved from

https://www.cdc.gov/mmwr/vol umes/69/ wr/mm 6928e3.htm?s_cid=mm6928e3_w

[26] Wood, J. T., \& Conrad, C. (1983). Paradox in the experiences of professional women. Western Journal of Speech Communication, 47, 305-322.

[27] Gallagher, K. M., \& Updegraff, J. A. (2012). Health message framing effects on attitudes, intentions, and behavior: A meta-analytic review. Annals of Behavioral Medicine, 43, 101-116. doi:10.1007/s12160-011-9308-7 